\title{
Cerebral infarct presenting with thunderclap headache
}

\author{
Bengt A. Edvardsson $\cdot$ Staffan Persson
}

Received: 14 February 2009/Accepted: 9 March 2009/Published online: 28 March 2009

(C) Springer-Verlag 2009

\begin{abstract}
A 73-year-old man presented with a thunderclap headache $(\mathrm{TCH})$, suggesting a subarachnoid haemorrhage. Neurological examination, computer tomography of the head, and cerebrospinal fluid examination were normal. Magnetic resonance imaging of the brain revealed a supratentorial cerebral infarct. No cerebral aneurysm could be detected. A TCH can be the presenting feature of many conditions. A formula for the diagnostic assessment of TCH should be established. The management of this type of headache is controversial. Articles differ in their conclusions and recommendations. An expansion of routine investigations should be performed in cases where the neurological examination, cerebrospinal fluid analysis, and computer tomography are normal. A TCH can be the primary clinical feature of a supratentorial cerebral infarct.
\end{abstract}

Keywords Thunderclap headache - Cerebral infarct . Vascular headache - Subarachnoid haemorrhage

\section{Introduction}

A formula for the diagnostic assessment of thunderclap headache $(\mathrm{TCH})$ should be established. The management of this type of headache is controversial The established diagnostic assessment of TCH includes a computer tomography (CT) of the head and cerebrospinal fluid (CSF) examination in order to exclude a subarachnoid haemorrhage. In patients whose CT scans and CSF analyses are normal, further testing is rarely considered to be indicated

B. A. Edvardsson $(\bowtie) \cdot$ S. Persson

Department of Clinical Sciences, Faculty of Neurology,

Lund University Hospital, 22185 Lund, Sweden

e-mail: Bengt.Edvardsson@med.lu.se by most clinicians [1]. However, others suggest that in circumstances where CT and CSF are normal, further diagnostic assessment with magnetic resonance imaging (MRI), magnetic resonance angiography (MRA) of the brain and neck, and magnetic resonance venography is necessary [2]. Articles differ in their conclusions and recommendations [3-5].

Thunderclap headache is described as a sudden, unusually severe headache which reaches its maximum intensity within a split second or, at most, a few minutes. The term was first used by Day and Raskin [6], in a case of sudden headache, where investigations revealed an unruptured cerebral aneurysm. About $25 \%$ of TCHs can be associated with subarachnoid haemorrhages [2]. A number of other disorders are known to be present with $\mathrm{TCH}$, e.g. cerebral venous thrombosis, cervical artery dissection and spontaneous intracranial hypotension [2]. TCH can also be a manifestation of primary headache, and it is now also recognised as an idiopathic headache. Headache is not uncommon in ischaemic stroke, but is usually overshadowed by other manifestations such as aphasia and neglect [7]. Prospective studies of the occurrence of headache in patients with ischaemic strokes reveal a frequency of 8-34\% [8].

We describe a patient who experienced a $\mathrm{TCH}$ as the primary clinical feature of a supratentorial cerebral infarct. Our patient underwent MRI and MRA that revealed a cerebral infarct. We suggest that an expanded assessment with MRI should be performed in similar cases even when the neurological examination, CSF analysis, and CT are normal.

\section{Case report}

A 73-year-old man appeared in the emergency department following an acute and sudden onset of severe headache. 
He experienced this episode of explosive headache when sitting down on a chair. The pain was located in the frontal region, it reached its maximum intensity in $<1 \mathrm{~min}$ and lasted for about $3 \mathrm{~h}$. There were no additional symptoms. He took $500 \mathrm{mg}$ of aspirin and was later taken to hospital. At the time of admission, the patient reported that the headache had resolved.

There was no previous history of headache. The patient's medical history revealed hypertension and diabetes mellitus. He did not smoke. His medications at admission included aspirin, atenolol, ramipril, and simvastatin.

Vital signs and physical examination were normal. Neurological examination was normal. Laboratory testing was within the normal range. Blood pressure monitoring revealed hypertension, reaching 190/95 mmHg. An electrocardiogram (ECG) showed sinus rhythm. CSF examination revealed a normal opening pressure $\left(180 \mathrm{mmH}_{2} \mathrm{O}\right)$, a normal closing pressure, a normal cell count and protein. A CT scan of the head was normal. An MRI of the brain revealed an acute ischaemic lesion in the right semiovale region (Fig. 1). An MRA was performed to exclude possible intracranial aneurysms, cerebral venous thrombosis, cervical artery dissection, and vasospasm. These investigations were normal. A brain CT was performed 3 days after the MRI and demonstrated a definitive cerebral infarct. Further investigations with ECG telemetry, MRA of the cervical arteries, and echocardiography were normal. The aetiology of the ischaemic lesion remains unknown. We assume that the stroke was due to small vessel disease. Further measures were taken to improve the medical treatment of his hypertension and diabetes mellitus. The patient could be discharged and remains well. At follow-up after 3- and 6 months, he reported no headache. He had no recurrence of headache after the first event.

\section{Discussion}

Our case shows that the assessment of TCH might have to be expanded with MRI to rule out a cerebral infarct. TCH is a rare manifestation of cerebral infarct. In the year 2006, a case report was published where $\mathrm{TCH}$ was the presenting feature of embolic cerebellar infarcts, in the absence of neurological findings [9]. Gossrau et al. [10] presented a similar case (cerebellar infarct) in 2008. To our knowledge, this is the first report of a TCH as the presenting feature of an otherwise asymptomatic supratentorial cerebral infarct.

The headache in ischaemic stroke can be abrupt or gradual in onset [11]. It is usually focal and mild [7]. The character of the headache is throbbing [7], or continuous and non-throbbing [11]. The severity of the headache is not related to the size of the infarct or the location of the lesion [7].

The mechanisms of headache in cerebral infarcts are multifactorial. It is likely that an activation of the trigeminovascular system in intracranial vessels seems to be essential for the production of headache in ischaemic stroke [12]. Headache is more common when stroke occurs in the area of the posterior circulation than in the anterior circulation [7]. The posterior circulation is more densely innervated by the trigeminal system, which may explain the frequency of headache in posterior circulation infarcts. An ischaemic stroke may cause the release of vasoactive neuropeptides from sensory afferents. This reaction may in turn result in an increased nociceptive input into the nervous system and head pain [12]. Primary TCH is a rare type of headache. The pathophysiology of primary $\mathrm{TCH}$ is unclear. One hypothesis is that excessive sympathetic activity or an abnormal vascular response to circulating catecholamines may be involved. This would explain the occurrence of TCH during physical activity, and in patients
Fig. 1 MRI, diffusionweighted imaging (DWI) (a), ADC map (b) demonstrating an acute ischemic lesion in the right periventricular white matter (centrum semiovale region)
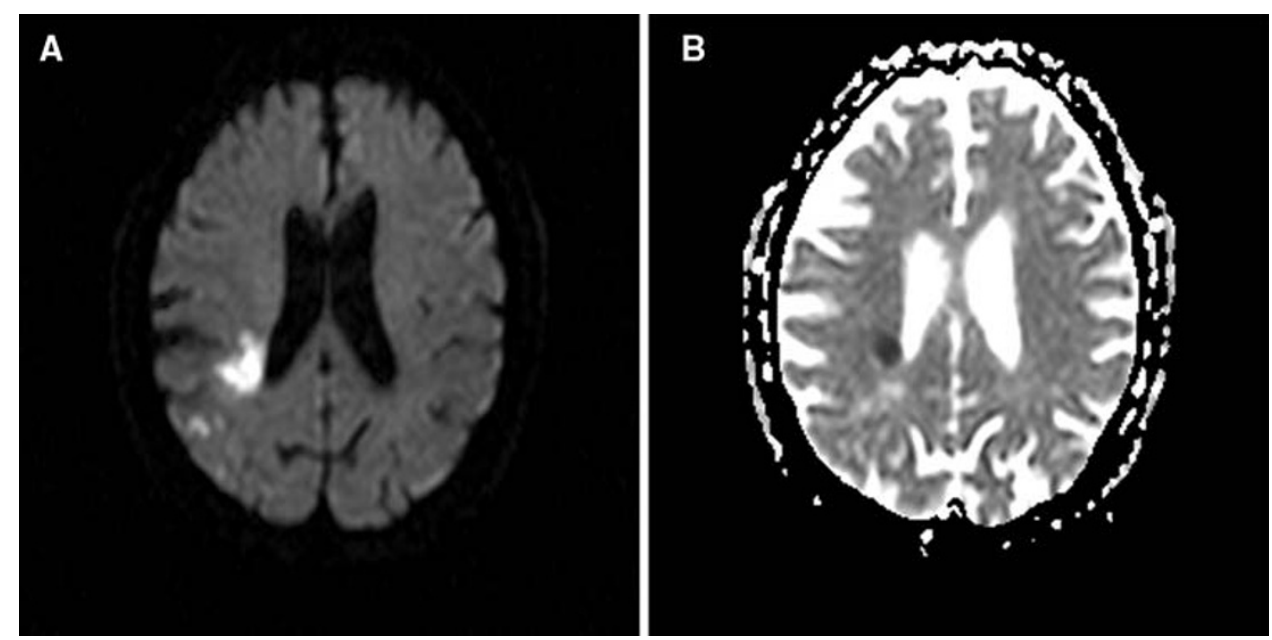
with pheocromocytoma. The mechanism of TCH induced by ischaemic stroke is unclear. The association needs to be elucidated in further studies.

We suggest that when a patient presents with a TCH an expanded assessment with MRI of the brain should be ordered to rule out a cerebral infarct, even when neurological examination, brain CT, and CSF examination are normal as in our case. It is also obvious that angiographic studies are necessary in some cases to rule out other secondary causes of TCH.

Conflict of interest None.

\section{References}

1. Edlow JA (2003) Diagnosis of subarachnoid hemorrhage in the emergency department. Med Clin North Am 21:73-87

2. Schwedt TJ, Matharu MS, Dodick DW (2006) Thunderclap headache. Lancet Neurol 5:621-631

3. Savitz SI, Edlow J (2008) Thunderclap headache with normal CT and lumbar puncture: further investigations are unnecessary: for. Stroke 39:1392-1393
4. Moussouttas M, Mayer SA (2008) Thunderclap headache with normal CT and lumbar puncture: further investigations are unnecessary: against. Stroke 39:1394-1395

5. Davis SM, Donnan GA (2008) Thunderclap headache: CT and lumbar puncture but occasionally more. Stroke 39:1396

6. Day JW, Raskin NH (1986) Thunderclap headache: symptom of unruptured cerebral aneurysm. Lancet 2:1247-1248

7. Vestergaard K, Andersen G, Nielsen MI, Jensen TS (1993) Headache in stroke. Stroke 24:1621-1624

8. Ferro JM, Melo TP, Oliveira V, Salgado AV, Crespo M, Canhão $\mathrm{P}$ et al (1995) A multivariate study of headache associated with ischemic stroke. Headache 35:315-319

9. Schwedt TJ, Dodick DW (2006) Thunderclap stroke: embolic cerebellar infarcts presenting as thunderclap headache. Headache 46:520-522

10. Gossrau G, Dannenberg C, Reichmann H, Sabatowski R (2008) Thunderclap headache caused by cerebellar infarction. Schmerz 22:82-86

11. Portenoy RK, Abissi CJ, Lipton RB, Berger AR, Mebler MF, Baglivo J (1984) Headache in cerebrovascular disease. Stroke 1984:1009-1012

12. Moskowitz MA, Buzzi MG, Sakas DE, Linnik MD (1989) Pain mechanisms underlying vascular headaches. Rev Neurol 145: 181-193 